\title{
Efficiency of low versus high airline pressure in stunning cattle with a pneumatically powered penetrating captive bolt gun
}

\author{
Steffan Edward Octávio Oliveira ${ }^{\mathrm{a}, \mathrm{b}}, *$, Neville George Gregory ${ }^{\mathrm{c}}$, Filipe Antonio Dalla Costa ${ }^{\mathrm{a}, \mathrm{b}}$, \\ Troy John Gibson ${ }^{\mathrm{c}}$, Mateus José Rodrigues Paranhos da Costa ${ }^{\mathrm{a}, \mathrm{b}}$ \\ a Programa de Pós-graduação em Zootecnia, Faculdade de Ciências Agrárias e Veterinárias, Universidade Estadual Paulista, 14.884-900 Jaboticabal, SP, Brazil \\ b Grupo de Estudos e Pesquisas em Etologia e Ecologia Animal, Departamento de Zootecnia, Faculdade de Ciências Agrárias e Veterinárias, Universidade Estadual Paulista, \\ 14.884-900 Jaboticabal, SP, Brazil \\ ${ }^{c}$ Royal Veterinary College, University of London, London, United Kingdom
}

\section{A R T I C L E I N F O}

\section{Keywords:}

Airline pressure

Bolt velocity

Consciousness

Rhythmic respiration

Shot

\begin{abstract}
A B S T R A C T
The efficiency of stunning cattle was assessed in 443 animals (304 pure Zebu and 139 crossbred cattle), being mainly mature bulls and cows. Cattle were stunned using a Jarvis pneumatically powered penetrating captive bolt gun operating with low (160-175 psi, $\mathrm{N}=82)$ and high (190 psi, $\mathrm{N}=363$ ) airline pressure, which was within the manufactures specifications. Signs of brain function and the position of the shots on the heads were recorded after stunning. Velocity of the captive bolt and its physical parameters were calculated. Cattle shot with low pressures showed more rhythmic respiration (27 vs. $8 \%, P<0.001$ ), less tongue protrusion (4 vs. $12 \%$, $P=0.03$ ) and less masseter relaxation ( 22 vs. $48 \%, P<0.001)$. There was an increased frequency of shots in the ideal position when cattle were shot with the low compared to high airline pressures (15.3 vs. 3.1\%). Bolt velocity and its physical parameters were significantly $(P<0.01)$ higher when using high pressure. Airline pressures below 190 psi are inappropriate when shooting adult Zebu beef cattle with pneumatically powered penetrating captive bolt guns.
\end{abstract}

\section{Introduction}

The aim of penetrative captive bolt stunning is to induce a deep and irreversible form of concussion prior to the act of slaughter (Gregory, 2007). Shooting an animal with pneumatically powered penetrating captive bolt guns is one of the most common methods of cattle stunning in large abattoirs. This method consists of delivering a blow to the animal's head, which is designed to penetrate its cranium, causing massive damage to the brain and induce insensibility.

The assessment of stunning efficiency is generally done by evaluating behavioral and physical signs of depth of concussion and include: the immediate collapse of the animal after stunning, which is used as an indicator of the potential loss of consciousness (Schepens \& Drew, 2004; Terlouw, Bourguet, \& Deiss, 2016); absence of corneal reflex, which indicates a large probability that the disruption is associated with a wider dysfunction, comprising part of the reticular formation, and thus with a state unconsciousness (Bourguet, Deiss, Tannugi, \& Terlouw, 2011; Sturges, 2005); absence of eye pursuit movements, which does not necessarily indicate unconsciousness, but its presence is considered indicative of the presence of consciousness (Terlouw et al., 2016); eyeball facing forward, as its rotation indicates that there is a risk of a shallower depth of unconsciousness or a return of consciousness (Atkinson, Velarde, \& Algers, 2013) and absence of rhythmic breathing, since this sign indicates that the medulla in the brain and also the spinal cord plus nerves (which control breathing movements in the body) are still functioning (Gregory, 2007).

As stated by Gibson, Mason, Spence, Barker, and Gregory (2015), insensibility is caused by a combination of direct damage to the brain and the kinetic energy delivered to the animal's head. The kinetic energy transmitted through the bolt depends upon its mass and is directly proportional to the square of its velocity. Dörfler, Troeger, Lücker, Schönekeß, and Frank (2014) observed that when shooting with cartridge powered captive bolt guns, only one third to one half of the potential energy of the cartridge is transformed into kinetic energy of the captive bolt (since part of its potential energy is probably wasted as heat energy when the cartridge is fired). Based on this, the authors concluded that efficiency of captive bolt devices powered by cartridge is rather low. On the other hand, pneumatically powered captive bolt

\footnotetext{
* Corresponding author at: Programa de Pós-graduação em Zootecnia, Faculdade de Ciências Agrárias e Veterinárias, Universidade Estadual Paulista, 14.884-900 Jaboticabal, SP, Brazil.

E-mail address: steffan_edward@yahoo.com.br (S.E.O. Oliveira).
} 
guns use compressed air as the potential energy when the gun is fired, which minimize energy to be wasted as heat as with cartridge powered guns. Thus, the air pressure level in the gun's air chamber before shooting may affect the velocity of the bolt, the amount of kinetic energy delivered to the animal's head and, consequently, the efficiency of stunning.

Although most of the gun manufacturers provide information about the operating airline pressure ranges, there are no studies examining the effects of different airline pressures on the efficiency of cattle stunning. Therefore, the objective of this study was to assess the efficiency of stunning cattle using pneumatically powered penetrating captive bolt guns operating with low and high airline pressures.

\section{Materials and methods}

This project was approved by the Committee of Ethical Use of Animals (Protocol number: 022754/14).

\subsection{Abattoirs description}

The study was carried out through nine days during the routine daily stunning and slaughter of cattle at two beef abattoirs belonging to the same company. Combined, both abattoirs slaughters approximately 1300 animals/day, mainly mature bulls (over $550 \mathrm{~kg}$ liveweight) and cows (over $400 \mathrm{~kg}$ liveweight). The animals were individually restrained in a pneumatic stunning pen equipped with a head yoke and then stunned by an experienced slaughterman with a pneumatically powered penetrating captive bolt gun (PCB). After the animal had rolled out of the stunning pen, it was shackled and then hoisted onto a bleeding rail, where a third slaughterman stuck it by inserting a knife into the thoracic cavity. According to the user's manual provided by the manufacturer, the operating airline pressure of the guns used at both abattoirs is within a range of $160-190$ psi (USSS-1, JARVIS ${ }^{\circledR}$ Jarvis Products Corporation; Middletown, CT, USA). The abattoirs are regulated by the Brazilian Federal Inspection Service.

\subsection{Animals and airline pressures}

Two levels of airline pressure were tested at two abattoirs: Low pressure, adjusted within the range of $160-175$ psi $(\mathrm{N}=82)$ and High pressure, set to $190 \mathrm{psi}(\mathrm{N}=363)$. The control and verification of the desired airline pressure was done through the pressurization system and manometers of each abattoir. A total of 176 Zebu pure (110 and 66 from abattoir A and B, respectively) and 267 crossbred Zebu (31 and 236 from abattoir A and B, respectively) were assessed for this study.

\subsection{Assessment of physical signals of brain function}

The state of consciousness and response to pain in stunned cattle were assessed by recording twelve physical signals in three different stages of the production line: with the animal on the ground, just after it had rolled out of the stunning pen (GR) and being hoisted (HO), and before bleeding, at the beginning of the bleeding rail (BL). A person, standing on the platform of the stunning pen, recorded the general information about the animals (breed, category, and gender), if they collapsed or not after the first shot and the interval between stunning and sticking. Another person recorded the physical signals of brain function at GR and HO, and a third person did it at BL. Shot accuracy was assessed at BL by placing a grid printed on transparent plastic onto the head of the shot cattle and measuring the deviation between the shot hole and the ideal shooting position, defined by Gregory (2007) as the cross-over point between imaginary lines drawn between the base of each horn and the corner of the eye on the opposite side of the head.

The following physical signs were recorded: rhythmic respiration (excluding spasmodic gasping and gagging), corneal reflex (assessed in response to light rubbing of the exposed cornea with a finger), palpebral reflex (evaluated in response to pinching the eyelid with two fingers), eyeball rotation (assessed from the presence of sclera in the exposed eye), response to nostril stimulation (assessed in response to scratching a fingernail inside the nostril), tremor (visible in the underside of the animal, originating in the muscles of the limbs and belly), righting reflex (defined as lateral turning of the head associated with apparent struggling movements), tongue protrusion (identified when animal's tongue protruded out at least $10 \mathrm{~cm}$ ), masseter relaxation (recognized as little or no resistance to the opening of the masseter), blood extravasation (blood flowing out of mouth and/or nostrils after stunning), tonic convulsion (rigid extension or contraction of legs) and clonic convulsion (assessed according to a 0-3 kicking score: $0=$ no kicking; $1=$ mild kicking; $2=$ vigorous kicking but not sufficient to delay shackling and sticking; $3=$ violent kicking activity which endangered staff).

\subsection{Bolt velocity measurements and determination of physical parameters}

A custom-built velocity meter (Solutions for Research, Silsoe, Bedford, UK) was used to measure velocity of the captive bolt when it was fired in air. The measurements were done with the airline pressure set to 160,175 and 190 psi. This device measures the time taken for the bolt to transect a series of seven infrared LEDs. Each LED is placed $4 \mathrm{~mm}$ apart. The time taken to transect consecutive LEDs is recorded as bolt velocity. Recorded data were stored through the velocity meter software for further analyses (2009 CBG Tester ${ }^{\circledast}$, Royal Veterinary College) of bolt velocity profile through the velocity meter and peak velocity. The mass of the dismantled captive bolt was measured with a precision laboratory balance and the following physical parameters were calculated:

(a) Momentum ( $p$, in Newton-second) of the captive bolt was calculated according to its mass ( $m$, in kilogram) and velocity ( $v$, in meters per second) by the formula

$p=m v$.

(b) Kinetic energy ( $\left.E_{\text {kin }}\right)$ of the bolt was calculated based on its mass ( $m$, in kilogram) and velocity ( $v$, in meters per second) by the formula

$E_{\mathrm{kin}}=\frac{1}{2} m v^{2}$.

(c) Energy density $(E)$ was calculated from the kinetic energy of the bolt divided by the bolt's cross-sectional area or effective impact area (A; Kneubuehl, Coupland, Rothschild, \& Thali, 2011).

$E=\frac{E_{k i n}}{A}=\frac{\frac{1}{2} m v^{2}}{\pi d^{2}}$

\subsection{Statistical analysis}

Data were analyzed by two-tailed Fisher Exact test with Graphpad software (2015 Graphpad Software, Inc). A completely randomized experimental design was used to compare the effects of treatments (airline pressures). The model included fixed effects of abattoir, day of data collection, treatments, and error (corresponding to randomized variation on the observations in the days of data collection and animal group), supposedly homoscedastic, independent and normally distributed. The frequency of physical signs was analyzed for significant differences using the Fisher Exact test. The animal and shots were adopted as experimental unit for analyses of physical signs and bolt velocity, respectively. Since there was no difference in captive bolt guns (CBG) and airline pressures used, the abattoir was considered as random effect. There was no effect of day of data collection on any variable studied. For the analyses of bolt velocity measurements, a 
Table 1

Prevalence of physical signs of brain function in cattle after being shot with pneumatic penetrating captive bolt gun at low airline pressure ( $L P=160-175 \mathrm{psi}$ ) and high airline pressure (HP $=190 \mathrm{psi}$ ) assessed on the ground, just after the animal had rolled out of the stunning pen (GR), just after being hoisted (HO), and at the bleeding rail (BL).

\begin{tabular}{|c|c|c|}
\hline Local of assessment and physical signals & $\begin{array}{l}\text { LP }(\mathrm{N}=82) \\
\text { (\% of occurrence) }\end{array}$ & $\begin{array}{l}\mathrm{HP}(\mathrm{N}=363) \\
\text { (\% of occurrence) }\end{array}$ \\
\hline \multicolumn{3}{|l|}{ Stunning pen } \\
\hline Immediate collapse after shot & 98 & 99 \\
\hline \multicolumn{3}{|l|}{ GR } \\
\hline Rhythmic respiration & $27^{\mathrm{a}}$ & $8^{\mathrm{b}}$ \\
\hline Righting reflex & 0 & 1 \\
\hline Tremor & 19 & 28 \\
\hline Masseter relaxation & $22^{\mathrm{b}}$ & $48^{\mathrm{a}}$ \\
\hline Tongue protrusion & $4^{\mathrm{b}}$ & $12^{\mathrm{a}}$ \\
\hline Responding to nostril stimulation & 5 & 3 \\
\hline Palpebral reflex - corneal reflex & 2 & 1 \\
\hline Eyeball rotation & 1 & 1 \\
\hline Tonic convulsion & 58 & 62 \\
\hline Clonic convulsion (score 1 ) & 16 & 20 \\
\hline Clonic convulsion (score 2 or 3 ) & 16 & 14 \\
\hline \multicolumn{3}{|l|}{$\mathrm{HO}$} \\
\hline Rhythmic respiration & 5 & 1 \\
\hline Righting reflex & 23 & 16 \\
\hline Tremor & 10 & 6 \\
\hline Tongue protrusion & 44 & 46 \\
\hline Blood extravasation & $1^{\mathrm{b}}$ & $22^{\mathrm{a}}$ \\
\hline Tonic convulsion & $8^{\mathrm{a}}$ & $0.3^{\mathrm{b}}$ \\
\hline Clonic convulsion (score 1 ) & 34 & 34 \\
\hline Clonic convulsion (score 2 or 3 ) & 27 & 25 \\
\hline \multicolumn{3}{|l|}{ BL } \\
\hline Rhythmic respiration & 2 & 2 \\
\hline Righting reflex & 5 & 3 \\
\hline Tremor & 10 & 4 \\
\hline Tongue protrusion & 61 & 61 \\
\hline Clonic convulsion (score 1 ) & 8 & 9 \\
\hline Clonic convulsion (score 2 or 3 ) & 7 & 6 \\
\hline
\end{tabular}

Frequencies in a row without a common superscript letter were significantly different $(P<0.05)$.

variance analysis was performed according to the completely randomized design model considering only the treatment effect (airline pressures). Multiple comparisons of the values of bolt velocities were performed using the Tukey-Kramer test. A probability level of $P<0.05$ was chosen as the limit for statistical significance in all tests and probability levels of $P \leq 0.10$ were considered as a tendency.

\section{Results}

\subsection{Physical signals of brain function}

There was a significant difference $(P<0.001)$ in rhythmic respiration, between the two airline pressures at GR. When shot with low airline pressure, more animals (27\%) presented rhythmic respiration than the group shot with high pressure (8\%). Low pressure also resulted in less tongue protrusion ( 4 vs. $12 \%, P=0.02$ ) and masseter relaxation (22 vs. $48 \%, P<0.001$ ) than high pressure. At HO, low pressure resulted in less blood extravasation ( 1 vs. $22 \%, P<0.001)$ and more tonic convulsion ( 8 vs. $0.3 \%, P=0.02$ ) than high pressure. There was a tendency towards statistical significance of more rhythmic respiration for low pressure at $\mathrm{HO}(5$ vs. $1 \%, P=0.06)$ and tremor at BL (10 vs. $4 \%, P=0.06$; Table 1).

\subsection{Shooting accuracy}

There was an increased frequency of shots in the ideal position when cattle where shot with the low compared to high airline pressures (Table 2; $P<0.001$ ). The percentage of shots that deviated more than two centimeters from the ideal shooting position was greater for high
Table 2

Frequency of shots at the ideal shooting position in cattle heads and the deviation in $\mathrm{cm}$ from that position, when shot with pneumatically powered penetrating captive bolt guns operating with low (LP $=160-175 \mathrm{psi})$ and high (HP = $190 \mathrm{psi}$ ) airline pressure.

\begin{tabular}{llll}
\hline $\begin{array}{l}\text { Shot deviation from the ideal shooting } \\
\text { position }(\mathrm{cm})\end{array}$ & $\begin{array}{l}\mathrm{LP}(\mathrm{N}=82) \\
(\% \text { of shots) }\end{array}$ & $\begin{array}{l}\text { HP }(\mathrm{N}=353) \\
(\% \text { of shots })\end{array}$ & $P$ \\
\hline Ideal shooting position & 15.3 & 3.1 & $<0.001$ \\
1 & 27.1 & 12.4 & 0.001 \\
2 & 22.6 & 19.2 & 0.64 \\
3 & 21.4 & 19.8 & 0.65 \\
4 & 8.3 & 18.1 & 0.01 \\
5 & 1.4 & 11.9 & 0.001 \\
6 & 1.4 & 8.8 & 0.01 \\
7 & 0 & 5.1 & 0.03 \\
8 & 2.5 & 1.4 & 0.62 \\
9 & 0 & 0.3 & 1 \\
\hline
\end{tabular}

pressure than low pressure (65.4 vs. 35\%, respectively; $P<0.001)$.

\subsection{Bolt physical parameters}

There was a significant difference $(P<0.05)$ in bolt velocity between the airline pressures. As the airline pressure was increased from 160 to 190 psi, bolt mean peak velocity increased. Bolt physical parameters, such as momentum, kinetic energy and energy density also showed a linear augmentation, with the highest airline pressure $(190 \mathrm{psi})$ being significantly different from the others $(P<0.05$; Table 3).

Fig. 1 is the mean velocity profiles of the captive bolt guns for the three airline pressures. The measurements for bolt velocity along the velocity meter showed that the peak velocity for all three airline pressures occurred when the bolt transected the fourth infrared LED, which was positioned $12 \mathrm{~mm}$ from the top of the velocity meter. The distance from the recessed bolt to this sensor was $98 \mathrm{~mm}$.

\section{Discussion}

To the best of our knowledge, this is the first study to evaluate the effects of airline pressure on the efficiency of pneumatic penetrative captive bolt stunning of cattle.

In spite of the relatively small difference in the levels of air pressure, the results found in this study demonstrate the importance of choosing high airline pressures instead of low, since cattle presented fewer signs of imperfect stunning and the PCB guns performed better.

Initially 36 and 46 cattle were shot with airline pressures of 160 and $175 \mathrm{psi}$, respectively. Following a significant proportion of animals showing signs of rhythmic respiration after the shot it was decided to end assessment of these pressures and to increase to $190 \mathrm{psi}$.

The position of the shots on the cattle heads did not explain why high pressure was more efficient than low pressures in stunning the cattle. There was not a higher frequency of shots at the ideal shooting position, which is described as the cross-over point between imaginary lines drawn between the base of each horn and the corner of the eye on the opposite side of the head (Gregory, 2007), at the higher airline pressure, but instead low pressures shots were more accurate than the high pressure shots (Table 2). Moreover, $65 \%$ of the low pressure shots were positioned within the recommended $2-\mathrm{cm}$ radius from the ideal shooting position (EFSA, 2004), against $34.6 \%$ of the high pressure shots. Potential reasons for differences in shot accuracy at different airline pressures include less care being taken in aiming the shot when using high airline pressures in the knowledge that there could be less risk of ineffective stunning at high pressures. In addition, the increased recoil associated with higher airline pressures could have influence the accuracy of shot position, as the operators generally shot with the muzzle not in contact with the head.

Instead, the likely explanation for cattle presenting less physical 


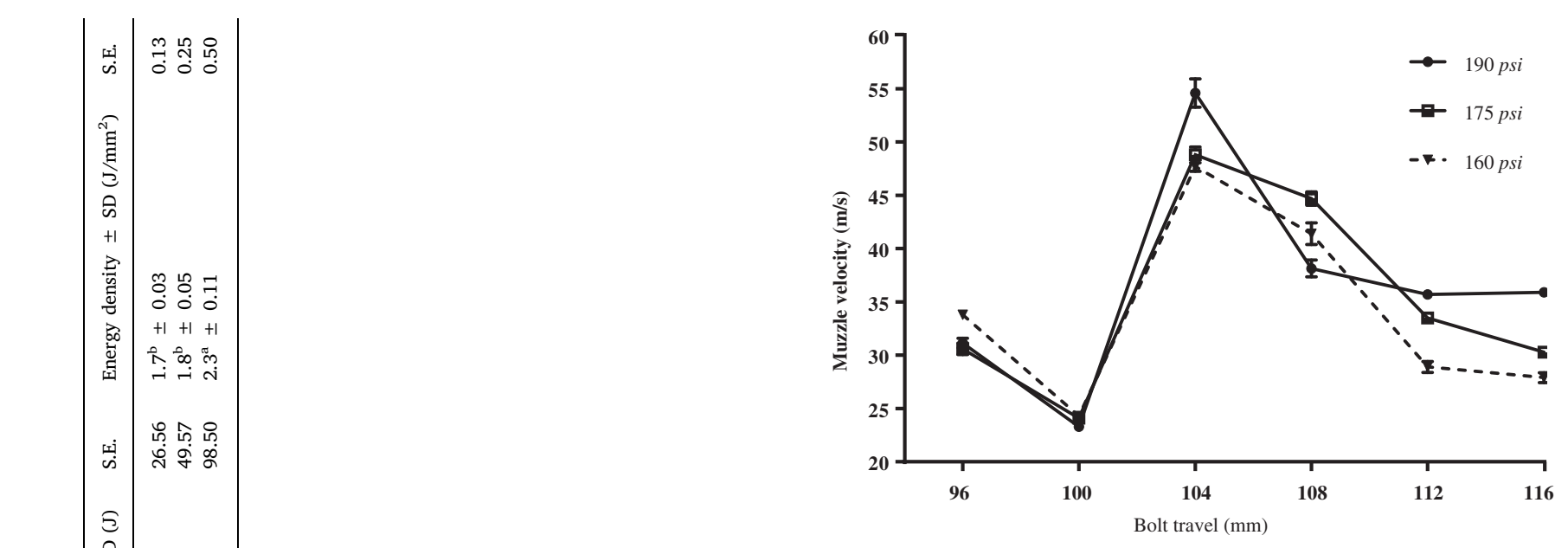

Fig. 1. Muzzle velocity profile according to the airline pressure.

signs of imperfect stunning after being shot with high pressure lies in the greater kinetic energy that is transferred to cattle's head through the bolt (Table 2). According to Daly and Whittington (1989), it is the kinetic energy transmitted to the cranium by the bolt that produces insensibility. In spite of the lower values of kinetic energy found for low pressure on this study, it is still in conformity with some author's recommendations, e.g. according to Blackmore (1985), the kinetic energy required to penetrate the head of adult European breed cattle was $127 \mathrm{~J}$, less than the recommendation presented by the Human Slaughter Association (1999), which states that an impact energy of at least 200 joules is necessary for an effective stun in adult cattle.

The kinetic energy delivered to the head during CBG stunning is affected to a much greater extent by variation in the velocity of the captive bolt as opposed to the mass of the bolt (Gibson et al., 2015). As reported by Gregory (2005) and Grandin (2013), the recommended minimum bolt velocity for Bos taurus steers, heifers, and cull cows is generally not $<55 \mathrm{~m} \cdot \mathrm{s}^{-1}$, and $70 \mathrm{~m} \cdot \mathrm{s}^{-1}$ for stunning young and mature bulls (Grandin, 2013; Gregory, 2007). However, the previous recommendations are based on cartridge-fired guns which have a lower bolt diameter compared to pneumatically powered guns, and so theoretically they could transfer less energy to the skull. In this study, the highest value of mean peak velocity of the bolt occurred with the high pressure treatment $\left(54.6 \mathrm{~m} \cdot \mathrm{s}^{-1}\right)$, being not enough to reach the recommended minimum velocity.

Despite its relevance to stunning, kinetic energy and head damage are not always correlated, since damage is not only due to energy transfer, but also to mechanical stress in the tissue (Koene, Boufker, \& Papy, 2008). Therefore, considering the requirements for head penetration by captive bolt, other physical parameters such as momentum and energy density should be taken into account.

The transfer of momentum from the bolt to the skull plays a crucial role when trying to achieve penetration. Since the penetrating bolt should have a small mass and a high velocity, it must result in an ultrashort time span during which the bolt is acting upon the skull. According to Karger (1995), because of inertia, the skull as a whole will not essentially move during transfer of impulse. Instead, during impact there will be a high transfer of momentum and energy locally, but no direct load on the entire skull. The result is the perforation of the skull without acceleration of the head. In humans, the most common forces involved in concussive traumatic brain injury are acceleration/deceleration of the freely moving head, resulting in rotational damage to the brain (Gibson et al., 2009). However, in cattle, the relatively large and immobile head supported by significant musculature reduces acceleration and deceleration (Finnie, 1995, 1997). The highest value of momentum found on this work occurred when shooting with high airline pressure (Table 3 ).

In this study, the mean values of energy density (amount of energy 
that can be stored in a given mass of a system) of the captive bolt, for the three airline pressure tested (Table 3), were higher than the energy density measurements required for causing penetrating wounds at any human anatomical region (Bir, Stewart, \& Wilhelm, 2005). However, there are no studies evaluating the minimum requirements of momentum or energy density of the captive bolt that leads to head penetration and effective stun in livestock species.

With regards to the physical signs, this study showed that when cattle were shot with high airline pressure they presented fewer signs indicating imperfect stunning, such as rhythmic respiration (see Table 1 at GR). According to Gregory (2007), this sign indicates that the medulla in the brain and also the spinal cord plus nerves (which control breathing movements in the body) are still functioning. When rhythmic respiration is present it is important that the animal is immediately restunned in the correct position (Grandin, 2013).

\section{Conclusions}

Despite the airline pressures tested in this study being in accordance with the operating airline range recommended by the manufacturer, it is concluded that airline pressures below $190 \mathrm{psi}$ are inappropriate when shooting adult Zebu beef cattle with pneumatically powered penetrating captive bolt guns. Due to insufficient information in the published literature about the physical parameters of penetrating captive bolts needed to stun adult beef cattle and the level of brain lesion resulted from bolt penetration according to the airline pressure, further research is required to improve the efficiency of cattle stunning and prevent suffering.

\section{Acknowledgements}

The authors would like to thank Everton Adriano Andrade, Carlos Alberto de Oliveira Silva and the researchers from Group ETCO, in special to Karen Camille Rocha Góis for all the help during the period of data collection. Sincere thanks go to CNPq (National Council of Technological and Scientific Development) for granting the scholarships to Steffan Edward Octávio Oliveira and Filipe Antônio Dalla Costa. The authors are grateful to FAPESP for the financial support to bring Dr. Neville George Gregory to Brazil, which participated integrally of this study and to JBS for the manpower and facilities usage. Thank also to Dr. Osmar Antônio Dalla Costa and Arlei Coldebella for assisting the data analysis.

\section{References}

Atkinson, S., Velarde, A., \& Algers, B. (2013). Assessment of stun quality at commercial slaughter in cattle shot with captive bolt. Animal Welfare, 22, 473-481.

Bir, C. A., Stewart, S. J., \& Wilhelm, M. (2005). Skin penetration assessment of less lethal kinetic energy munitions. Journal of Forensic Science, 50, 1426-1429.

Blackmore, D. K. (1985). Energy requirements for the penetration of heads of domestic stock and the development of a multiple projectile. Journal of the British Veterinary Association, 116, 36-40.

Bourguet, C., Deiss, V., Tannugi, C. C., \& Terlouw, E. M. C. (2011). Behavioural and physiological reactions of cattle in a commercial abattoir: Relationships with organisational aspects of the abattoir and animal characteristics. Meat Science, 88, 158-168.

Daly, C. C., \& Whittington, P. E. (1989). Investigation into the principal determinants of effective captive bolt stunning of sheep. Research in Veterinary Science, 46, 406-408.

Dörfler, K., Troeger, K., Lücker, E., Schönekeß, H., \& Frank, M. (2014). Determination of impact parameters and efficiency of 6.8/15 caliber captive bolt guns. International Journal of Legal Medicine, 128, 641-646.

EFSA (2004). Welfare aspects of the main systems of stunning and killing the main commercial species of animals; opinion of the Scientific Panel on Animal Health and Welfare on a request from the Commission related to welfare aspects of the main systems of stunning and killing the main commercial species of animals. The EFSA Journal, 45, 1-29.

Finnie, J. W. (1995). Neuropathological changes produced by non-penetrating percussive captive bolt stunning of cattle. New Zealand Veterinary Journal, 43, 183-185.

Finnie, J. W. (1997). Traumatic head injury in ruminant livestock. Australian Veterinary Journal, 75, 204-208.

Gibson, T. J., Johnson, C. B., Murrell, J. C., Mitchinson, S. L., Stafford, K. J., \& Mellor, D. J. (2009). Electroencephalographic responses to concussive non-penetrative captivebolt stunning in halothane-anaesthetised calves. New Zealand Veterinary Journal, 57, 90-95.

Gibson, T. J., Mason, C. W., Spence, J. Y., Barker, H., \& Gregory, N. G. (2015). Factors affecting penetrating captive bolt gun performance. Journal of Applied Animal Welfare Science, 18, 222-238.

Grandin, T. (2013). Making slaughterhouses more humane for cattle, pigs, and sheep. Annual Review of Animal Biosciences, 1, 491-512.

Gregory, N. G. (2005). Recent concerns about stunning and slaughter. Meat Science, 70, $481-491$.

Gregory, N. G. (2007). Stunning and slaughter. In N. G. Gregory (Ed.), Animal welfare and meat science (pp. 191-212). (2nd ed.). Wallingford, UK: CAB Publishing.

HSA, Humane Slaughter Association (1999). Humane killing of livestock using firearms. (Guidance notes n. 3, p. 11). Wheathampstead: Humane Slaughter Association, The Old School, Brewhouse Mill.

Karger, B. (1995). Penetrating gunshots to the head and lack of immediate incapacitation. I. Wound ballistics and mechanisms of incapacitation. International Journal of Legal Medicine, 108, 53-61.

Kneubuehl, B. P., Coupland, R. M., Rothschild, M. A., \& Thali, M. J. (2011). Wound ballistics, basics and applications. Berlin, Germany: Springer-Verlag, 4.

Koene, B., Boufker, F., \& Papy, A. (2008). Kinetic non-lethal weapons. In T. Hupkens, \& H. Monsuur (Eds.), Netherlands annual review of military studies. Sensors, weapons, C4L and operations research (pp. 9-24). Netherlands: T.M.C. Asser Press.

Schepens, B., \& Drew, T. (2004). Independent and convergent signals from the pontomedullary reticular formation contribute to the control of posture and movement during reaching in the cat. Journal of Neurophysiology, 92, 2217-2238.

Sturges, B. K. (2005). Neuro-ophthalmology: The visible nervous system. Proceedings of the 2nd annual veterinary neurology symposium. Davis, USA: University of California.

Terlouw, C., Bourguet, C., \& Deiss, V. (2016). Consciousness, unconsciousness and death in the context of slaughter. Part II. Evaluation methods. Meat Science, 118, 147-156. 